\title{
Anti-thrombotic therapy in non-ST elevation acute coronary syndrome
}

Author:

Keith A.A. Fox

Address for correspondence: Professor Keith A.A. Fox Cardiovascular Research Division of Medical and Radiological Sciences The University of Edinburgh Chancellors Building 49 Little France Crescent

Edinburgh

EHIO 4SB

Email: k.a.a.fox@ed.ac.uk
ABSTRACT Platelet activation and thrombin generation are implicated in the pathogenesis of acute coronary syndrome, in the development of major thrombotic complications of the condition, and in the interventional treatments to treat obstructive coronary lesions (principally, percutaneous coronary intervention). Despite treatment with aspirin and heparin there remained a clinically important risk of thrombotic complications both in hospital and following discharge. Newer anti-platelet therapies (thienopyridines and glycoprotein Ilb/llla inhibitors) reduced platelet mediated complications, but with an increase in bleeding risk. Similarly, low molecular weight heparins reduced thrombotic complcations but with a modest increase in bleeding. Newer anti-thrombins (anti Xa inhibitors and direct thrombin inhibitors) demonstrate similar or improved efficacy, but with reduced bleeding. Insufficient attention has been paid to reducing bleeding complications and recent evidence suggests that major bleeding conveys a significant increase in the risk of death. In addition, clearance of antithrombotic agents by the kidney is impaired in those with renal dysfunction, including in the elderly, and this may contribute to the risks of bleeding. In unselected populations with non-ST elevation ACS more than half the population have a creatinine clearance below $60 \mathrm{ml} / \mathrm{min}$. Reducing the doses of anti-thrombins in patients with renal dysfunction may reduce bleeding complications. The optimal anti-thrombotic strategy in patients with non-ST elevation ACS requires the clinician to consider not only the risk of the patient for thrombotic complcations, but also the hazards of bleeding. Newer anti-thrombotic agents, for the first time, offer potential benefits in bleeding risk with similar or improved efficacy.

\section{INTRODUCTION}

The term "acute coronary syndrome" describes the clinical manifestations of disruption of coronary arterial plaque complicated by intra-luminal thrombosis and distal embolization. The plaque disruption is superimposed on a variable degree of obstruction to the coronary lumen. In consequence, the spectrum of severity of the syndrome is determined by the volume of myocardium affected and the extent of ischaemia and myocyte necrosis ${ }^{(1)}$. With total or sub-total coronary occlusion the patient commonly presents with ST elevation myocardial infarction (MI) and emergency primary percutaneous intervention $(\mathrm{PCl})$ is the preferred reperfusion strategy. If $\mathrm{PCl}$ is unavailable, thrombolysis substantially improves survival and outcome. In the remaining spectrum of ACS the condition is characterized by partial obstruction of the coronary lumen (occasionally, complete obstruction and well developed collaterals) and a variable degree of thrombotic occlusion('). This review will focus on non-ST elevation ACS, where clear evidence supports the use of both anti-platelet and anti-thrombin therapy. Such therapies also need to be seen in the context of percutaneous or surgical revascularization.

Previously, the risks of non-ST elevation ACS have been underestimated in comparison to those surviving to hospital with ST elevation $\mathrm{MI}^{(2,3)}$. A similar proportion of ST and non-ST elevation Ml patients die in the first 6 months after presentation (9-12\%) and approximately one in five will require emergency re-hospitalization. Thus, there is the need for anti-thrombotic therapy (in addition to secondary prevention measures) during the acute in-hospital and post-discharge phases. Recent advances in anti-thrombotic and revascularization therapies have been shown to reduce serious cardiac complications, re-hospitalizations and deaths in patients with ACS. However, these improvements in outcome require prompt and effective triage systems and consistent application of evidence-based therapies. International studies suggest that a substantial shortfall exists in the application of guideline and evidence based therapies in clinical practice.

\section{ANTI-PLATELET THERAPY}

\section{Aspirin}

Evidence for the benefit of aspirin is not new, but the evidence base is very substantial and combined analyses remain powerful and compelling. The most recent update of the Anti-Thrombotic Trialists' Collaboration is based upon 287 studies in 135,000 patients (4). It demonstrates a highly significant reduction in the risk of myocardial infarction/stroke/vascular death as a result of anti-platelet therapy (principally aspirin), versus control. ${ }^{(3,4)}$ Overall, the event rates were $13.2 \%$ in control patients and $10.7 \%$ in those treated with anti-platelet therapy, a 22\% relative risk reduction. In acute $\mathrm{Ml}$, and in other high risk patients, the absolute and relative risk reductions were greater: 23 per I,000 fewer vascular deaths and I 3 per I,000 fewer Mls. Thus, abundant evidence supports the use of aspirin in patients with acute coronary syndromes. Additional anti-platelet therapy requires evidence of benefit on top of aspirin, rather than as an alternative to aspirin. For maintenance therapy, recent data suggest that bleeding risk doubles for aspirin doses above versus below $100 \mathrm{mg}$ daily, with no improved efficacy ${ }^{(5,6)}$.

\section{Thienopyridines (ADP antagonists)}

Thienopyridines inhibit ADP mediated platelet aggregation. Initial studies were conducted with ticlopidine but this has been superceded by clopidogrel, on account of superior safety. The CURE trial tested clopidogrel in 12,562 non-ST segment elevation ACS patients on top of background treatment and aspirin ${ }^{(5)}$. A 2.1\% absolute risk reduction (20\% relative risk reduction $\mathrm{p}<0.000 \mathrm{I}$ ) occurred in the frequency of non-fatal $\mathrm{MI}$, stroke or cardiovascular death ${ }^{(5)}$. The treatment effect was evident early (within the first 24 hours of starting therapy) and the absolute benefits were greatest in the first 3 months of treatment. Nevertheless, the relative risk reduction was similar beyond 3 months ${ }^{(6)}$.Approximately $1 \%$ more patients experienced major bleeding, but there was no significant excess of lifethreatening bleeding nor hemorrhagic strokes ${ }^{(5)}$. Nevertheless, in view of 
the irreversible nature of the ADP antagonism, current guidelines suggest that clopidogrel should be withheld for 5 days prior to CABG surgery ${ }^{(7)}$. In candidates for very urgent CABG a small molecule glycoprotein Ilb/llla inhibitor (eptifibatide or tirofiban) can be used prior to surgery ${ }^{\left({ }^{8}\right)}$.

In non-ST segment elevation ACS, the ESC and AHAACC guidelines recommend at least 9 and up to 12 months' treatment with clopidogrel ${ }^{(8)}$. Longer term treatment in patients with a spectrum of vascular risk was examined in the large scale CHARISMA trial ${ }^{(9)}$. Overall, the results do not support long-term therapy with clopidogrel in addition to aspirin. Those with ischaemic events (Ml, stroke or peripheral vascular events) appear to benefit more than patients simply at high vascular risk ${ }^{(9)}$ (primary prevention) but the evidence is not sufficently robust to form the basis of guideline recommendations. There is evidence for the use of clopidogrel in acute ST elevation myocardial infarction (treated with thrombolysis) from the CLARITY and COMMIT trials.

Thienopyridines reduce the risk of stent thrombotic occlusion and are now part of standard treatment, in combination with aspirin, in all patients undergoing elective $\mathrm{PCl}$. Recent data on late stent thrombosis suggest that with drug eluting stents at least 12 months of clopidogrel and aspirin are required. With $\mathrm{PCl}$ in $\mathrm{ACS}$ there is evidence for benefit for I year of treatment (PCI CURE and CREDO trials) ${ }^{(10)}$.

\section{Glycoprotein Ilb/llla receptor antagonists}

The glycoprotein Ilb/llla receptor plays a key role in platelet aggregation through linkages involving fibrinogen or von Willebrand Factor. Intravenous glycoprotein Ilb/llla receptor antagonists have been extensively tested in patients with acute coronary syndromes and in a meta-analysis of all the major randomised trials the absolute risk reduction for death or myocardial infarction at 30 days was 1\% ( I I.8\% control versus 10.8\% with GPIlb/Illa) (II-13). The absolute treatment benefit was largest in high risk patients; in particular those with evidence of troponin release or those undergoing acute $\mathrm{PCl}$. Among those without troponin elevation or without $\mathrm{PCl}$ no significant benefits were observed with GPllb/llla administration.

The CREDO and ISAR-REACT trials have helped to resolve the question of whether clopidogrel plus glycoprotein Ilb/llla receptor antagonists may be required in patients undergoing PCl (10-14). In CREDO about half of the patients received glycoprotein IIb/llla antagonists (a non-randomized subset) and two-thirds had presented with an acute coronary syndrome. The frequency of $\mathrm{MI}$, stroke or death at one year was reduced with clopidogrel from $11.5 \%$ to $8.5 \%(p=0.02)$, with similar risk ratios in the presence or absence of GPIIb/IIla inhibitors. In ISAR-REACT 2 there was additional benefit (relative risk of death, $\mathrm{Ml}$, revascularization $=0.75 ; 95 \% \mathrm{Cl}$, 0.58$0.97 ; \mathrm{P}=0.03$ ) with abciximab treatment in the presence of background treat-ment of aspirin and clopidogrel (loading dose $600 \mathrm{mg}$ given more than 2 hours prior to $\mathrm{PCl})^{(14)}$
In summary, aspirin provides clear evidence of benefit in patients with acute coronary syndromes and robust evidence supports the use of clopidogrel in patients presenting with non-ST elevation ACS (at least up to 9-12 months). Extensive evidence supports the use of intravenous glycoprotein Ilb/lla inhibitors in high risk patients with ACS, especially those in whom the troponin level is elevated and/or who are to undergo acute $\mathrm{PCl}(12,13)$.

\section{ANTI-THROMBINTHERAPY}

Thrombin is critical in the generation of fibrin and it is also a potent stimulator of platelet activation. Thrombin activation promotes monocyte chemotaxis, mitogenesis, increased permeability of the vascular wall and secretion of cytokines and growth factors from smooth muscle cells. Thus thrombin inhibition should not be seen in isolation. Effective anti-thrombotic treatment requires inhibition of platelet function and inhibition of thrombin (I).

\section{Unfractionated heparin (UFH) and low molecular weight heparin (LMWH)}

Although unfractionated heparin has been used extensively in ACS it suffers from practical difficulties in maintaining anti-thrombin activity within the therapeutic range (influenced by acute phase proteins and the binding to anti-thrombins). In many settings it has been replaced by LMWH. There is clear evidence that a form of heparin (either unfractionated or $L M W H$ ), is superior to placebo in patients with $\operatorname{ACS}\left({ }^{8}, 15,16\right)$. The meta-analysis of trials of UFH/LMWH versus control demonstrates a reduction in absolute rates of death or Ml from $7.4 \%$ to $4.5 \%$ (odds ratio $0.53,95 \% \mathrm{Cl} 0.38-0.73$ ) (17). The meta-analysis of all the trials of LMWH versus unfractionated heparin has demonstrated a modest but significant advantage in death or myocardial infarction (odds ratio 0.91 95\% Cl 0.83-0.99) ${ }^{(18,19)}$. Heterogeneity exists among the low molecular weight heparins and a meta-analysis of the two trials of enoxaparin (ESSENCE andTIMI I I B) has demonstrated a significant reduction in death or myocardial infarction compared with unfractionated heparin (odds ratio 0.82, 95\% Cl 0.69-0.97). However, these trials predated modern interventional therapy and thienopyridine antagonists. Regarding safety, the combined analysis of LMWH versus UFH suggests a similar safety profile for $\mathrm{LMWH}$ and unfractionated heparin in the presence or absence of glycoprotein Ilb/llla inhibitors (major bleeds: 3.9\% LMWH vs 3.7\% UFH, odds ratio I.I, 95\% Cl 0.96-I.13) (18). SYNERGY was a largescale trial testing enoxaparin versus UFH in the context of intervention (20). Overall, there was no significant advantage for enoxaparin (similar efficacy) but a modest increase in bleeding. The study strongly suggested that bleeding hazards were greater in those switching from enoxaparin to UFH for catheterization (perhaps due to the combined effect of both antithrombins). The risks of bleeding were lower if the patient continued on the same anti-thrombin ${ }^{(20)}$.

\section{Direct thrombin inhibitors}

Direct anti-thrombins may provide advantages over the indirect inhibitors (unfractionated and low molecular weight heparin). In earlier trials in ACS patients there was no clear benefit for the direct thrombin inhibitors. GUSTO 
IIB trial failed to demonstrate a sustained benefit for hirudin over UFH and in OASIS 2 the early benefits were no longer significant during follow-up (21). Nevertheless, combined analysis of the hirudin studies suggests a relative risk

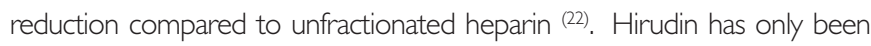
approved for patients with heparin induced thrombocytopenia $(H I T)$.

\section{Bivalirudin}

In ACUITY (23) 1 3,819 patients with moderate to high risk NSTE-ACS were randomized in an open-label trial of patients undergoing invasive (PCl) treatment. The design was complex. There were three unblinded treatment groups: standard treatment with either UFH or LMWH ( $n=4603)$ combined with GP IIb/Illa inhibitor; or bivalirudin combined with GP IIb/Illa inhibitor treatment $(n=4604)$, or bivalirudin alone $(n=46 / 2)$. In the two arms with GP IIb/Illa inhibitors, patients were randomized to receive either upstream GP Ilb/llla inhibitors, or administration in the catheterisation laboratory. The randomization was stratified for pre-treatment with clopidogrel, which was administered prior to $\mathrm{PCl}$ in $62.3 \%$ of patients. Coronary angiography was performed in $98.9 \%, \mathrm{PCl}$ in $56.3 \%$, and CABG in $11.1 \%$, while $32.6 \%$ had no intervention. The study found no significant difference between standard UFH/LMWH plus GPIlb/llla, and the combination of bivalirudin and GPIlb/llla for the ischaemic composite endpoint (death, $\mathrm{Ml}$ or unplanned revascularization) at 30 days (7.3\% vs. 7.7\% respectively, RR 1.07 [0.92-1.23], $p=0.39$ ), nor for major bleeding (5.7\% vs. 5.3\%, RR 0.93 [0.78- I. I0], $p=0.38$ ). There was also no difference between the standard UFH/LMWH combined with GPIlb/llla inhibitors compared with bivalirudin alone, for the ischaemic composite endpoint (7.3\% vs. 7.8\%, RR I.08 [0.93-1.24], p=0.32), but there was a lower bleeding rate with bivalirudin ( $5.7 \%$ vs $3.0 \%$, RR 0.53 [0.43-0.65], p<0.00 I). However, the risk of ischaemic endpoints tended to be higher with bivalirudin alone (RR I.08 [0.93-1.24]).The composite clinical outcome in ACUITY (ischaemic events and major bleeds at 30 days) was significantly lower in the bivalirudin alone group ( 1 1.7\% vs 10.1\%, RR 0.86 [0.77-0.94], p=0.015) compared to the standard combination. In high risk patients, there was a trend towards a higher rate of ischaemic events with bivalirudin vs. UFH/LMWH, especially among patients not pre-treated with clopidogrel prior to $\mathrm{PCl}$. In these patients, a significantly higher risk of ischaemic events with bivalirudin compared to heparin plus GP IIb/llla inhibitors was observed (9.1\% vs 7.1\%, RR I.29 [1.03-1.63]), with a significant interaction $(p=0.05)$ between pretreatment with clopidogrel and the effect of bivalirudin alone. It is noteworthy that in ACUITY the definition of major bleeding included access site haematoma $>5 \mathrm{~cm}$. Analyses of the bleeding results could be better understood if standard definitions of major bleeding had been applied.

\section{Anti-Xa inhibitors}

In addition to inhibition of thrombin, low molecular weight heparins partially inhibit factor $\mathrm{X}_{\mathrm{a}}$, located more proximally in the coagulation cascade. Newer specific inhibitors of $\mathrm{Xa}$ have been developed, including the pentasaccharide, fondaparinux. Anti-Xa agents inhibit thrombin generation, they do not directly inhibit thrombin activity. Direct comparisons with low molecular weight heparins have shown advantages for fondaparinux over enoxaparin for the prevention of DVT (odds ratio 0.55, 95\% Cl 0.73-0.36). It must be noted that the dose of enoxaparin for deep vein thrombosis prophylaxis is half that for ACS.

In non-ST elevation ACS, a dose-ranging study of fondaparinux was performed against enoxaparin in 1, 147 patients ${ }^{(24)}$. The $2.5 \mathrm{mg}$ dose of fondaparinux was chosen for subsequent phase III trials, as reflecting best efficacy/safety profile. Fondaparinux (alone) was also tested in a phase II trial in $\mathrm{PCl}$, at doses of $2.5 \mathrm{mg}$ or $5 \mathrm{mg}$, vs. standard dose of $\mathrm{UFH}$, and was shown to have similar efficacy and safety to UFH (25). In that study, angiographic thrombi were reported in the UFH group, but were reported with higher frequency in both fondaparinux groups. The study did not observe a measurable impact of such thrombi on the rate of clinical events, including peri-procedural MI ${ }^{(25)}$.

In the phase III OASIS-5 study (26), 20,078 patients with NSTE-ACS were randomized to receive subcutaneous fondaparinux ( $2.5 \mathrm{mg}$ daily), versus enoxaparin ( $1 \mathrm{mg} / \mathrm{kg}$ twice daily) for up to 9 days (average 5.3 days). The primary outcome of death, myocardial infarction or refractory ischaemia at 9 days was very similar (5.7\% enoxaparin vs. $5.8 \%$ fondaparinux, HR I.0I, 95\% Cl 0.90-1.13). This satisfied the criteria for noninferiority (26). However, major bleeds were halved with fondaparinux (2.2\% fondaparinux vs. $4.1 \%$ enoxaparin, HR 0.52, 95\% $0.44-0.61, p<0.00$ I), and the composite outcome of death, myocardial infarction, refractory ischaemia or major bleeding also favoured fondaparinux, 7.3\% compared to $9.0 \%$ with enoxaparin (HR 0.8I, 95\% Cl 0.73-0.89, $\mathrm{p}<0.00 \mathrm{I}){ }^{(26)}$. Major bleeding was an independent predictor of death, which was lower with fondaparinux at 30 days $(2.9 \%$ vs. $3.5 \%, \mathrm{HR} 0.83,95 \% \mathrm{Cl} 0.7 \mathrm{I}-0.97, \mathrm{p}=0.02)$, and at 6 months ( $5.8 \%$ vs. 6.5\%, HR 0.89,95\% Cl 0.80-I.00, p=0.05). The composite outcome of death, Ml or stroke was significantly lower with fondaparinux at 6 months: | I.3\% vs. 12.5\%, HR 0.89, 95\% Cl 0.82-0.97, p=0.007 (26).

\section{ANTI-THROMBOTIC THERAPY FOR PCI PROCEDURES IN ACS}

Platelet inhibition with aspirin and systemic anticoagulation with unfractionated heparin (UFH) has been the reference standard for $\mathrm{PCl}$ since this therapy was first applied ${ }^{(27)}$. In order to reduce the PCl-related thrombotic complications, this treatment is combined with clopidogrel and GP Ilb/llla inhibitors. The current guideline recommendation, based only on empiric evidence, is to give UFH as an iv bolus of $100 \mathrm{IU} / \mathrm{kg}$ or about 50-60 U $/ \mathrm{kg}$ if GP IIb/Illa inhibitors are used (27). The efficacy of UFH is monitored by activated clotting time (ACT). However, the relation between ACT values with a given bolus of UFH and the rate of clinical events remains uncertain; in consequence the real utility of $\mathrm{ACT}$ monitoring remains undetermined.

Direct thrombin inhibition with bivalirudin and GP Ilb/llla inhibitors has been shown to be at least as effective but with a lower risk of bleeding compared with UFH/LMWH plus GP IIb/llla inhibitors ${ }^{(28-29)}$. 
Low MW heparins have been used in the setting of $\mathrm{PCl}$, and of these most of the evidence has been obtained with enoxaparin. Previously, due to a lack of clinical studies, patients on LMWH were either switched to UFH, or UFH was added on top of enoxaparin before going to the cathlab. More recent data have shown that no additional UFH is needed if $\mathrm{PCl}$ is carried out within 6 to 8 hours following the last subcutaneous injection of enoxaparin ${ }^{(30)}$. After 6-8 hours following the last injection of enoxaparin, an additional $0.3 \mathrm{mg} / \mathrm{kg}$ iv bolus of enoxaparin is recommended.

The SYNERGY trial tested enoxaparin ( $\mathrm{mg} / \mathrm{kg}$ twice daily) or UFH in double blind design in 4,687 NSTE-ACS patients undergoing PCl. It demonstrated similar efficacy in both groups, but with a higher risk of bleeding associated with post-randomization crossover from one antithrombotic agent to another ${ }^{(20)}$. In the STEEPLE trial enoxaparin was used at reduced doses of $0.5 \mathrm{mg} / \mathrm{kg}$ or $0.75 \mathrm{mg} / \mathrm{kg}$ iv bolus, in comparison with standard iv doses of $\mathrm{UFH}$, in 3,258 patients undergoing elective $\mathrm{PCl}$ (31). A significant reduction in the primary endpoint was observed in the $0.5 \mathrm{mg} / \mathrm{kg}$ of enoxaparin (5.9\% vs. $8.5 \% \mathrm{UFH}$, odds ratio $0.69,95 \% \mathrm{Cl}-4.7$ to -0.6 , $\mathrm{p}=0.0 \mathrm{I}$ ), while the $0.75 \mathrm{mg} / \mathrm{kg}$ arm was non-inferior to UFH (6.5\% vs. $8.5 \%$ $\mathrm{UFH}$, odds ratio $0.7695 \% \mathrm{Cl}-4.0$ to $0.0, p=0.05 \mathrm{I}$ ). There was a reduction in major bleeding, which was significant in both enoxaparin arms, as compared to the UFH arm, but there was no significant difference in the rate of bleeding complications in patients who received GP IIb/IIla inhibitors (31). The rate of ischaemic events (death and MI) was not significantly different between the two groups, but the STEEPLE trial had insufficient power to reliably detect a difference in efficacy.

Fondaparinux, the anti- $\mathrm{Xa}$ inhibitor, was tested in the setting of $\mathrm{PCl}$ in

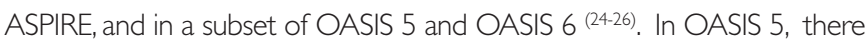
was a trend towards a higher rate of $\mathrm{PCl}$-related coronary complications in the fondaparinux group, (9.5\% fondaparinux versus $8.6 \%$ enoxaparin, OR I. I [0.94- I.29], $p=0.2$ I), but without a significant impact on the rate of ischaemic events at 9 and 30 days. There was a significantly lower rate of vascular access site complications (3.3\% fondaparinux vs. $8.1 \%$ enoxaparin, RR 0.4 I [0.33-0.5 I], p <0.00 I), and a significantly lower rate of bleeding complications with fondaparinux as compared to enoxaparin (2.2\% vs. 4. I\%, RR 0.52 [0.44-0.6I], p<0.00 I at 9 days and 3.1\% vs. 5.0\%, RR 0.62 [0.54-0.72], $\mathrm{p}>0.00 \mathrm{I}$ at 30 days). However, a higher rate of catheter-related thrombi was observed with fondaparinux as compared with enoxaparin (0.9\% vs. $0.4 \%, R R 3.6$ [1.6-7.8], $p=0.00$ I. This higher rate of catheter thrombosis was also observed in the setting of primary PCl in STEMI in the OASIS-6 study ${ }^{(32)}$. However, the frequency of catheter-related thrombus was reduced in OASIS-5 and eliminated in OASIS- 6 by the administration of UFH prior to or during PCl. Pragmatically, a standard dose of UFH is recommended on top of fondaparinux, if fondaparinux is used as the antithrombin prior to $\mathrm{PCl}$.

\section{BLEEDING IN ACUTE CORONARY SYNDROME}

Although bleeding is recorded as the most common complication of therapy in ACS, the significance of bleeding has not been fully appreciated. In addition, several different definitions have been used in clinical trials to grade bleeding severity. For example, the terms "severe, life-threatening, major or minor", have different qualifying criteria in trials using TIMI, GUSTO or OASIS definitions ${ }^{26,33)}$. In consequence, the frequency of bleeding is difficult to compare across studies.

Nevertheless, the frequency of major bleeding ranges from 2\% to $8 \%$ across the spectrum of acute coronary syndromes (ACS) depending on the frequency of invasive procedures and on the anti-thrombotic and antiplatelet therapy ${ }^{(20,34,35)}$. Data from registries generally reflect a population at higher risk and with greater comorbidity than that seen in clinical trials. In the CRUSADE registry conducted in the US, blood transfusion used as a surrogate marker of major bleeding and transfusion was performed in more than 15\% of patients ${ }^{(36)}$. In the multinational GRACE registry the overall incidence of major bleeding was $3.9 \%$ in patients with ST-segment elevation myocardial infarction (STEMI) and $4.7 \%$ in patients with non-ST segment elevation acute coronary syndromes (NSTE-ACS), and 2.3\% in patients with unstable angina ${ }^{(37)}$.

\section{Is it possible to predict the risk of bleeding in ACS?}

Similar predictors of bleeding were indentified in the CRUSADE and GRACE registries ${ }^{(37,38)}$. Independent predictors of major bleeding were advanced age (odds ratio (OR) 1.22 per 10-year increase, $p=0.0002$ ), female sex $(O R$ I.36, $p=0.01$ I6), history of bleeding $(O R$ 2. I $8, p=0.014)$, percutaneous coronary intervention ( $O R \quad 1.63, p=0.0005)$, history of renal insufficiency (OR I.53, $p=0.0062$ ), use of llb/lla inhibitors (OR 1.86, $p=0.000$ I) (Table I) (37). Excessive doses of drugs, especially in elderly patients or those suffering from renal failure, may also lead to an increased risk of bleeding ${ }^{(38)}$. These risk factors have been confirmed in other reports,

\begin{tabular}{|c|c|c|c|}
\hline Variable & Adjusted OR & $95 \% \mathrm{Cl}$ & P-value \\
\hline Age (per 10-year increase) & 1.22 & $1.10-1.35$ & 0.0002 \\
\hline Female sex & 1.36 & $1.07-1.73$ & 0.0116 \\
\hline History of renal insufficiency & 1.53 & $1.13-2.08$ & 0.0062 \\
\hline History of bleeding & 2.18 & $1.14-4.08$ & 0.014 \\
\hline $\begin{array}{l}\text { Mean arterial pressure } 1.14 \\
\text { (per } 20 \mathrm{mmHg} \text { decrease) }\end{array}$ & $1.02-1.27$ & 0.019 & \\
\hline Diuretics & 1.91 & $1.46-2.49$ & $<0.0001$ \\
\hline LMWH only & 0.68 & $0.50-0.92$ & 0.012 \\
\hline LMWH and $\mathrm{UFH}^{*}$ & 0.72 & $0.52-0.98$ & 0.035 \\
\hline GP IIb/llla blockers only & 1.86 & $1.43-2.43$ & $<0.0001$ \\
\hline Thrombolytics and GP IIb/llla blockers & 4.19 & $1.68-10.4$ & 0.002 \\
\hline IV inotropic agents & 1.88 & $1.35-2.62$ & 0.0002 \\
\hline Right-heart catheterisation & 2.01 & $|.38-2.9|$ & 0.0003 \\
\hline
\end{tabular}

Hosmer-Lemeshow goodness of fit test $P$-value $=0.70 ;$ C-statistic $=0.73$. 
including those from clinical trials. The critical role of renal dysfunction was confirmed in the OASIS-5 and EXTRACT studies, with the risk of major bleeding independently linked to the severity of renal dysfunction ${ }^{(39)}$. It is remarkable that a steep increase in bleeding risk is observed for moderate to mild levels of renal dysfunction. In OASIS-5, as in the GRACE registry, an increase in bleeding was observed with only mild impairment of creatinine clearance $(\mathrm{CrCl} 80 \mathrm{ml} / \mathrm{min})$. The risk is much higher for creatinine clearance between 30 and $60 \mathrm{ml} / \mathrm{min}$ and higher still for severe renal dysfunction $(\mathrm{CrCl}<30 \mathrm{ml} / \mathrm{min})$. Future trials are needed to define the appropriate dose of anti-thrombotic agents in the context of mild to moderate renal dysfunction.

\section{The impact of bleeding on prognosis}

Evidence from trials and registries demonstrates that major bleeding has a powerful impact on prognosis. In the GRACE registry, major bleeding predicted an increased risk of hospital death, with an odds ratio of 1.64 $(1.18-2.28, p<0.00 \mathrm{I})^{(37)}$. From a large meta-analysis of registries and trials, including more than 30,000 patients, major bleeding is associated with a fourfold increase in risk of death, a fivefold increase in risk of recurrent $M$ and a threefold increase in risk of stroke at 30 days $(5,37,40)$. Pooled data from four multicentre randomized clinical trials of patients with ACS, $(26,452$ patients), demonstrated a stepwise increase of the risk for death depending on the severity of bleeding (from mild, moderate to severe, using the GUSTO scale).

The hazard ratios for death at one month were 1.6,2.7 and I0.6 for mild, moderate and severe bleeding respectively, and at 6 months I.4,2.1 and 7.5 respectively ${ }^{(41)}$. Beyond 30 days, the risks of bleeding are lower, but are still present, as modern treatment of NSTE-ACS includes the use of dual anti-platelet therapy for 9 to 12 months ${ }^{(5.9)}$. A similar impact on prognosis has been demonstrated for both procedure-related and non- procedurerelated bleeding (41).

The mechanisms of the increase in mortality after bleeding have not been fully defined. Several factors contribute to the worse outcome associated with bleeding. The direct haemodynamic complications and immediate complications of bleeding only contribute part of the risk. Indirect effects, including the impact on renal function and potential deleterious effect of transfusion, may contribute to the mortality risk. In addition, bleeding triggers a pro-thrombotic and pro-inflammatory state. A key component of the risk may be the consequence of discontinuation of anti-platelet and anti-thrombotic therapy, leading to activation of the thrombotic cascade and ischaemic complications.

\section{CONCLUSIONS}

Pharmacologic and interventional therapy of acute coronary syndrome has changed markedly over the past decade. Evidence from large-scale randomized trials supports the use of dual anti-platelet therapy (aspirin plus thienopyridine) across the spectrum of ACS, and triple therapy (with glycoprotein Ilb/Illa inhibitors) in higher risk patients, especially in the context of PCl. Unfractionated heparin has been the reference standard antithrombin therapy, but recent trial evidence has demonstrated that greater benefit is derived from newer anti-thrombotic therapy (low MW heparin, anti-Xa inhibitors, direct anti-thrombins). The OASIS 5 trial demonstrated improved outcome with fondaparinux (lower bleeding and mortality) in non-ST elevation ACS patients compared with enoxaparin and OASIS 6 demonstrated improved outcome compared with control (unfractionated heparin or no heparin) in ST elevation ACS. The optimal balance of efficacy and safety (predominantly bleeding risk) is critical in improving patient outcomes. Newer anti-thrombotic therapy (for example fondaparinux, bivalirudin) produce less bleeding. Tailoring therapy to the individual patient's risks and potential benefits is critical.

\section{REFERENCES:}

I. Fox KAA, Management of Acute Coronary Syndromes: an update. Heart 2004 90: 698 - 706. Also published as a book Education in Heart Volume I pp I5 - 22 (BM) books) 2004

2. Fox KAA, Dabbous $\mathrm{OH}$, Goldberg RJ, Pieper KS, Eagle KA, Van de Werf $\mathrm{F}$ Avesum A, Goodman SG, Flather MD, Anderson FA Jr, Granger CB, for the GRACE Investigators: Prediction of risk of death and myocardial infarction in the six month following presentation with ACS: a prospective, multinational, observational study (GRACE). (BMJ on line doi: I 0.1 I 36/bmj.38985.64648I.55 published 10 October 2006)

3. Cairns JA, Singer J, Gent M, Holder DA, Rogers D, Sackett DL, et al. One year mortality outcomes of all coronary and intensive care unit patients with acute myocardia infarction, unstable angina or other chest pain in Hamilton, Ontario, a city of 375,000 people. Can J Cardiol 1989:5(5):239-46.

4. Anti-thrombotic Trialists Collaboration. Collaborative meta-analysis of randomized trials of antiplatelet therapy for prevention of death, myocardial infarction, and stroke in high risk patients. BMJ 2002;324(7329):7I-86

5. Yusuf S, Zhao F, Mehta SR, Chrolavicius S, Tognoni G, Fox KAA. Effects of clopidogrel in addition to aspirin in patients with acute coronary syndromes without ST-segment elevation. N Engl J Med 200 I:345(7):494-502.

6. Budaj A, Yusuf S, Mehta SR, Fox KAA, Tognoni G, Zhao F, et al. Benefit of clopidogrel in patients with acute coronary syndromes without ST-segment elevation in various risk groups. Circulation 2002:106(13): 1622-6.

7. Fox KAA, Mehta SR, Peters R, Zhao F, Lakkis N, Gersh B], et al. Benefits and risks of the combination of clopidogrel and aspirin in patients undergoing surgical revascularization for non-ST-elevation acute coronary syndrome: the Clopidogrel in Unstable angina to prevent Recurrent ischaemic Events (CURE) Trial. Circulation 2004; I I ( I 0): I 202-8

8. Bertrand ME, Simoons ML, Fox KAA, Wallentin LC, Hamm CW, McFadden E, De Feyter PJ, Specchia G, Ruzyllo W. Management of acute coronary syndromes in patients presenting without persistent ST-segment elevation. European Heart Journal 2002, 23:1809- 1840

9. Bhatt DL, Fox KAA, Hacke W, Berger PB, Black HR, Boden WE, et al. Clopidogrel and aspirin versus aspirin alone for the prevention of atherothrombotic events. N Engl J Med 2006;354(16): 1706-17.

10. Steinhubl SR, Berger PB, Mann JT, 3rd, Fry ET, DeLago A, Wilmer C, et al. Early and sustained dual oral antiplatelet therapy following percutaneous coronary intervention: a randomized controlled trial. JAMA 2002;288(19):241 I-20.

I I. Kong DF, Hasselblad V, Harrington RA, White HD, Tcheng JE, Kandzari DE, et al. Metaanalysis of survival with platelet glycoprotein Ilb/llla antagonists for percutaneous coronary interventions. Am J Cardiol 2003;92(6):65।-5. 
12. Boersma E, Akkerhuis KM, Theroux P, Califf RM, Topol El, Simoons ML. Platelet glycoprotein Ilb/llla receptor inhibition in non-ST-elevation acute coronary syndromes: early benefit during medical treatment only, with additional protection during percutaneous coronary intervention. Circulation 1999; 100(20):2045-8.

13. Boersma E, Harrington RA, Moliterno DJ, White H, Theroux P, Van de Werf F, et al. Platelet glycoprotein Ilb/lla inhibitors in acute coronary syndromes: a meta-analysis of all major randomized clinical trials. Lancet 2002;359(9302): 189-98.

14. Kastrati A, Mehilli J, Neumann FJ, Dotzer F, ten Berg J, Bollwein $H$, et al. Abciximab in patients with acute coronary syndromes undergoing percutaneous coronary intervention after clopidogrel pretreatment: the ISAR-REACT 2 randomized trial. JAMA 2006;295(I3): 1531-8.

15. Harrington RA, Becker RC, Ezekowitz M, Meade TW, O'Connor CM, Vorchheimer DA, et al. Antithrombotic therapy for coronary artery disease: the Seventh ACCP Conference on Antithrombotic and Thrombolytic Therapy. Chest 2004; | 26(3 Suppl):5 I3S-548S.

16. Collins R, MacMahon S, Flather M, Baigent C, Remvig L, Mortensen S, et al. Clinical effects of anticoagulant therapy in suspected acute myocardial infarction: systematic overview of randomised trials. Bmj 1996;313(7058):652-9.

17. Oler A, Whooley MA, Oler J, Grady D. Adding heparin to aspirin reduces the incidence of myocardial infarction and death in patients with unstable angina. A meta-analysis. JAMA 1996;276(I0):81।-5

18. Eikelboom JW, Anand SS, Malmberg K, Weitz JI, Ginsberg JS, Yusuf S. Unfractionated heparin and low-molecular-weight heparin in acute coronary syndrome without STelevation: a meta-analysis. Lancet 2000;355(9219): 1936-42.

19. Petersen JL, Mahaffey KW, Hasselblad V, Antman EM, Cohen M, Goodman SG, et al. Efficacy and bleeding complications among patients randomized to enoxaparin or unfractionated heparin for antithrombin therapy in non-ST-segment elevation acute coronary syndromes: a systematic overview. JAMA 2004;292(I):89-96.

20. Ferguson J], Califf RM, Antman EM, Cohen M, Grines CL, Goodman S, et al. Enoxaparin vs. unfractionated heparin in high-risk patients with non-ST-segment elevation acute coronary syndromes managed with an intended early invasive strategy: primary results of the SYNERGY randomized trial. JAMA 2004;292(1):45-54.

21. Organization to Assess Strategies for Ischaemic Syndromes (OASIS-2) Investigators. Effects of recombinant hirudin (lepirudin) compared with heparin on death, myocardial infarction, refractory angina, and revascularization procedures in patients with acute myocardial ischaemia without ST-elevation: a randomized trial. Lancet 1999;353(9151):429-38.

22. Direct Thrombin Inhibitor Trialists' Collaborative Group. Direct thrombin inhibitors in acute coronary syndromes: principal results of a meta-analysis based on individual patients' data. Lancet 2002;359(9303):294-302.

23. Stone GW, McLaurin BT, Cox DA, Bertrand ME, Lincoff AM, Moses JW, et al. Prospective, Randomized Comparison of Heparin Plus Glycoprotein Ilb/llla Inhibition and Bivalirudin With or Without Glycoprotein Ilb/llla Inhibition in Patients with Acute Coronary Syndromes:The ACUITYTrial. N Engl J Med 2006;In press.

24. Simoons ML, Bobbink IW, Boland J, Gardien M, Klootwijk P, Lensing AW, et al. A dose-finding study of fondaparinux in patients with non-ST-segment elevation acute coronary syndromes: the Pentasaccharide in Unstable Angina (PENTUA) Study. J Am Coll Cardiol 2004:43(| 2):2183-90.

25. Mehta SR, Steg PG, Granger CB, Bassand JP, Faxon DP, Weitz Jl, et al. Randomized, blinded trial comparing fondaparinux with unfractionated heparin in patients undergoing contemporary percutaneous coronary intervention: Arixtra Study in Percutaneous Coronary Intervention: a Randomized Evaluation (ASPIRE) Pilot Trial. Circulation 2005; I II (1 I):1390-7

26. Yusuf S, Mehta SR, Chrolavicius S, Afzal R, Granger CB, Budaj A, et al. Efficacy and Safety of Fondaparinux compared to Enoxaparin in 20,078 patients with acute coronary syndromes without ST-segment elevation. The OASIS (Organization to Assess Strategies in Acute Ischaemic Syndromes)-5 Investigators. N Engl J Med 2006;354( I 4): | 464-76.

27. Silber S, Albertsson P, Aviles FF, Camici PG, Colombo A, Hamm C, et al. Guidelines for percutaneous coronary interventions. The Task Force for Percutaneous Coronary Interventions of the European Society of Cardiology. Eur Heart J 2005;26(8):804-47.

28. Bittl JA, Chaitman BR, Feit F, Kimball W, Topol EJ. Bivalirudin versus heparin during coronary angioplasty for unstable or postinfarction angina: Final report reanalysis of the Bivalirudin Angioplasty Study. Am Heart J 200 I; I 42(6):952-9.

29. LincoffAM, Kleiman NS, Kereiakes DJ, Feit F, Bittl JA, Jackman JD, et al. Long-term efficacy of bivalirudin and provisional glycoprotein Ilb/lla blockade vs. heparin and planned glycoprotein Illb/llla blockade during percutaneous coronary revascularization: REPLACE2 randomized trial. JAMA 2004:292(6):696-703.

30. Hirsh J, Guyatt G, Albers GW, Schunemann HJ, (Eds). The Seventh ACCP Conference on Antithrombotic and Thrombolytic Therapy, Evidence-Based Guidelines. Chest 2004; 1 26: 172S-696S
31. Montalescot G, White HD, Gallo R, Cohen M, Steg PG, Aylward PE, et al. Enoxaparin versus unfractionated heparin in elective percutaneous coronary intervention. N Engl J Med 2006;355(10): 1006-17.

32. YusufS, Mehta SR, Chrolavicius S,Afzal R, Granger CB, Budaj A, et al. Effects of Fondaparinux, a factor $\mathrm{Xa}$ inhibitor, on mortality and reinfarction in patients with acute myocardial infarction presenting with ST-segment elevation. Organization to Assess Strategies for Ischaemic Syndromes (OASIS)-6 Investigators. JAMA 2006;295(| 3): I 519-30.

33. Antman EM, McCabe CH, Gurfinkel EP,Turpie AG, Bernink PJ, Salein D, et al. Enoxaparin prevents death and cardiac ischaemic events in unstable angina/non-Q-wave myocardial infarction. Results of the thrombolysis in myocardial infarction (TIMI) I I B trial. Circulation 1999; 100( I5): | 593-60 |

34. PRISM Investigators. A comparison of aspirin plus tirofiban with aspirin plus heparin for unstable angina. Platelet Receptor Inhibition in Ischaemic Syndrome Management (PRISM) Study Investigators. N Engl J Med I998;338(2 I): | 498-505.

35. Rao SV, O'Grady K, Pieper KS, Granger CB, Newby LK, Mahaffey KW, et al. A comparison of the clinical impact of bleeding measured by two different classifications among patients with acute coronary syndromes. J Am Coll Cardiol 2006:47(4):809-16.

36. Bhatt DL, Roe MT, Peterson ED, Li Y, Chen AY, Harrington RA, et al. Utilization of early invasive management strategies for high-risk patients with non-ST-segment elevation acute coronary syndromes: results from the CRUSADE Quality Improvement Initiative. JAMA 004:292(17):2096- 104.

37. Moscucci M, Fox KAA, Cannon CP, Klein W, Lopez-Sendon J, Montalescot G, et al. Predictors of major bleeding in acute coronary syndromes: the Global Registry of Acute Coronary Events (GRACE). Eur Heart J 2003;24(20): 1815-23.

38. Yang $X$, Alexander KP, Chen AY, Roe MT, Brindis RG, Rao SV, et al. The implications of blood transfusions for patients with non-ST-segment elevation acute coronary syndromes: results from the CRUSADE National Quality Improvement Initiative. J Am Coll Cardiol 2005;46(8): I 490-5.

39. Collet JP, Montalescot G, Agnelli G,Van de Werf F, Gurfinkel EP, Lopez-Sendon J, et al. NonST-segment elevation acute coronary syndrome in patients with renal dysfunction: benefit of low-molecular-weight heparin alone or with glycoprotein Ilb/llla inhibitors on outcomes. The Global Registry of Acute Coronary Events. Eur Heart J 2005;26(21):2285-93.

40. Rao AK, Pratt C, Berke A, Jaffe A, Ockene I, SchreiberTL, et al.Thrombolysis in Myocardial Infarction (TIMI) Trial--phase I: hemorrhagic manifestations and changes in plasma fibrinogen and the fibrinolytic system in patients treated with recombinant tissue plasminogen activator and streptokinase. J Am Coll Cardiol 1988; I I ( I): I - I I.

4I. Rao SV, O'Grady K, Pieper KS, Granger CB, Newby LK, Van de Werf F, et al. Impact of bleeding severity on clinical outcomes among patients with acute coronary syndromes. Am J Cardiol 2005;96(9): I 200-6. 